\title{
NIKE's General Company Analysis Based on It 2020 Annual Report
}

\begin{abstract}
Xuqing Liu
Beijing National Day School, Beijing,100039, China

Corresponding author's e-mail: Vivian.wang@cas-harbour.org

ABSTRACT

The year 2020 is a gathering of world sports events, such as the Olympic Games, the European Cup. Due to the COVID19 outbreak this year, various kinds of professional sports competitions have been canceled or postponed, thus the sports industry has been hit all over the world. NIKE, an American brand, which has been the leader of the sporting goods industry for years, is also affected by the explosion of COVID-19. In the report of NIKE 2020, the great changes in NIKE's financial performance reveal the economic impacts that were caused by the global epidemic situation. By collecting data and interpreting the official annual financial report, NIKE's financial performance, the company's strengths, weaknesses, opportunities, and threats in 2021 were analyzed in this article. Besides, with NIKE as an example that reflects the trend of the sports industry and develops online digital services, this article can be a reference for the sports industry to run better businesses in the future.
\end{abstract}

Keywords: NIKE, SWOT analysis, epidemic situation, company analysis, sporting goods industry

\section{INTRODUCTION}

At the beginning of 2020, the COVID-19 spread rapidly across countries. As several sports events have been delayed and people could not get out of their houses, the sports industry (especially the sporting goods industry) has been affected greatly. 2020 is a year that challenges the company and exposes their latent problems, thus the main purpose of this article is to reflect the underlying defects and suggests possible directions for further development of the sporting goods industry by analyzing NIKE's performance in 2020. By getting familiar with NIKE, the article would figure out how COVID-19 influences the company. All analyses are based on the content of NIKE's official financial statement and report. The article would finally come up with some suggestions due to the general analysis above. This paper will provide general information about NIKE and explain deeper views of this company. It also represents the development of the sporting goods industry and shows the possible ways of development that may benefit them in the long run.

\section{INTRODUCTION OF NIKE}

In the report of the 2019 world's top five hundred companies list, NIKE was ranked 341st. NIKE has abundant experience in how to construct a strong consumer products company and the NIKE brand has been spread to several regions over the world. Competing with other companies in the same industry, NIKE has great strengths and also, some weaknesses that need to be improved (are explained in detail in the following parts). However, the revenues it received every year, and its high visibility makes it become the top company in the world FMGG industry.

\section{SWOT ANALYSIS}

\subsection{Strengths}

\subsubsection{Business aspects}

Firstly, NIKE is a worldwide big brand that has a wide product range and lots of patents. Generally, NIKE consists of six key categories of its business, which are Running, NIKE Basketball, the Jordan Brand, Football and Training, and Sportswear [1]. Moreover, NIKE also produces products for targeted groups of people, such as 
kids and athletes. NIKE's business includes sports equipment, apparel, shoes, and other relevant groceries. Up to 2016, NIKE has registered 19,500 patents protecting properties of NIKE and are the core of NIKE's business, such as technologies and designs. On contrary, Adidas has roughly 2,400 patents [2]. Therefore, by holding these patents, NIKE could be able to expand its scale and creating unique products. The various products respond to market trends by offering numerous numbers of it and satisfying consumers' needs most largely.

Secondly, customers have great brand loyalty to NIKE and NIKE maintains high-quality cooperation with endorsers. NIKE was set up in 1967, it aims to create high-quality products and offer customers goods that adopt new technology. When it comes to brand loyalty, which is the consumer preference to buy a certain brand. According to (Tuominen, 1992) brand loyalty is nothing but the regular purchase of the same brand over time. In the research, the result shows that $55 \%$ of the participants claimed that they were purchasing the same brand for the past 15 years [3]. This shows the brand loyalty of the consumers towards Nike.

Besides, NIKE has already developed business with celebrities such as Michael Jordan. By analyzing the annual NIKE financial statement, the Jordan brand creates about 3,000 million dollars revenues on average per year in recent three years [1]. Nike has totally 284
NBA players under contract while only 77 players are endorsed by Adidas. Jordan, also owned by Nike Inc, has 35. Brands have several endorsements are Peak, 11; Under Armour, 11; Reebok, 4; Li-Ning, 4; Anta, 3; Spalding, 2; and And 1, 2. What is more, Ball'n, 361 Degrees, New Balance, Qiaodan and Brandlblack have one endorsement [4]. As a result, the high-quality relationship between NIKE and its endorsers could be a strength that many other sport equipment companies cannot be able to obtain easily and effective cooperation with stars could create greater brand influence.

\subsubsection{Financial aspects}

According to [1], in 2020, NIKE's financial performance is strongly affected by the emergence of COVID-19, though NIKE's first three quarters earned more in contrast with fiscal 2019, the profits and sales performance that declined in the fourth quarter makes the whole financial performance in fiscal 2020 worse than fiscal 2019. Revenues declined $4 \%$ to $\$ 37.4$ billion (for the first nine months, revenues grow by $7 \%$, for the fourth quarter, revenues declined 38\%). The NIKE Brand, declined $4 \%$ including currency changes. NIKE's total income before income taxes decreased by $40 \%$ in 2020. The operating and administrative expenses and bad debt expense increased.

Table 1 NIKE Financial Performance In Different Regions, 2020 (compared with 2019)

\begin{tabular}{|c|c|c|}
\hline Regions & $\begin{array}{c}\text { Total Revenues (including } \\
\text { currency changes) }\end{array}$ & $\begin{array}{c}\text { Earnings Before Interest And } \\
\text { Taxes }\end{array}$ \\
\hline North America & $-9 \%$ & $-26 \%$ \\
\hline Greater China & $+11 \%$ & $+5 \%$ \\
\hline Europe, Middle East, and Africa & $-1 \%$ & $-23 \%$ \\
\hline The Asia Pacific and Latin America & $+1 \%$ & $-11 \%$ \\
\hline
\end{tabular}

Table 2 General Performance Of NIKE in 2020

\begin{tabular}{|c|c|}
\hline Cash Ratio & 1.06 \\
\hline Return On Equity & $29.7 \%$ \\
\hline Return On assets & $9.2 \%$ \\
\hline Current Ratio & 2.5 \\
\hline
\end{tabular}

Firstly, NIKE has a moderate financial capability, as it has adequate capital resources and a steady gross margin. According to the NIKE, NEC. Consolidated Statement of Income, NIKE receives stable revenues, which is about 3 to 4 billion from 2016 to 2020[1]. Moreover, in the same period, the gross margin of NIKE has been maintained at a relatively steady level, which is about $44 \%$. Through these data, NIKE presents its capability to earn revenues and makes the ratio of gross profit to the revenue remains at a particular level. $44 \%$ gross margin is a very large number for all companies [1], which means that NIKE makes its largest profit and relatively lowest cost of production. Both the stability of the received revenue and the gross margin show NIKE is a globalized company that has a great ability to earn and manage capital resources, and also, sustain its gross margin even in the COVID-19 period. 
Secondly, NIKE has a stable cash dividend. As shown in the tab.3, NIKE has stable cash dividends, which is keep increasing from 2016 to 2020. It is worth noticing that the cash dividends per common share tend to rise year by year, which is a good signal for investors that they might gain more cash dividends once they invest in NIKE. Lavish and stable cash dividends present NIKE financial capability and stability, which could be important features that investors pay attention to.

Table 3 2016-2020 Cash dividends declared per common share of NIKE

\begin{tabular}{|c|c|c|c|c|c|}
\hline & 2020 & 2019 & 2018 & 2017 & 2016 \\
\hline $\begin{array}{c}\text { Cash dividends declared per common } \\
\text { share }\end{array}$ & 0.955 & 0.86 & 0.78 & 0.70 & 0.62 \\
\hline
\end{tabular}

\subsection{Weakness}

Firstly, Enormous factories and manufacturers of NIKE are concentrated in Southeast Asia. For fiscal 2020, contract factories in Vietnam, Indonesia, and China manufactured approximately $50 \%, 24 \%$, and $22 \%$ of total NIKE Brand footwear, and for the total NIKE brand apparel, factories in Vietnam, China, and Cambodia each occupy $28 \%, 23 \%$, and $12 \%$ [1]. Hence, a large portion of factories is concentrated in these three areas, especially Vietnam, Southeast Asia. Concentrated factories may be strongly influenced by new policies and natural hazards. Therefore, NIKE should create an equal distribution of factories to minimize potential risks.

Secondly, NIKE has a debt structure that needs to be optimized. Due to NIKE, NEC. Consolidated Balance Sheets, the total liability of the company is 23,287 million dollars, thus, the liability asset ratio is $74.3 \%$ [1]. In comparison with other companies in the sporting goods industry, such as DICK's Sporting Goods' liability asset ratio, which is 53\% in fiscal 2020, NIKE has a very high ratio number [5]. A high percentage of liability asset ratio may be a potential problem if there are emergent events take place and the company is no longer be able to pay for these debts. NIKE should further improve its debt structure in case of events like COVID-19 happen.

\subsection{Opportunities}

Firstly, NIKE could consider expanding its business in many potential areas, such as China. NIKE's operating segments, which are defined by geographic regions, show the structure of the Company's internal organization. Because of the impacts of COVID-19, the total NIKE, inc earnings before interest and taxes declined 26\% in North America, 23\% in EMEA, 11\% in the Asia Pacific and Latin America [1]. However, the only segment that has increased earnings in 2020 is Greater China, which increased 5\% earnings before interest and taxes. Nike's retail price in The Chinese market is about 500 to 1,000 yuan per pair, but local brands are $20 \%$ to $50 \%$ cheaper, so Nike is still at a disadvantage in terms of price in Greater China [6]. As a result, NIKE should consider the status of different segments and estimate segments' value correctly to gain revenues efficiently. For instance, NIKE could use more money to forge cheaper products that are particular for the Chinese and fit their tastes, which will help NIKE become more competitive in the Greater China market.

Secondly, to create a sustainable business, NIKE may develop a digital platform to adapt to the current tendency of network development, due to the positive impact of the epidemic on business performance and the future development space.

It is worth to mention that since many offline stores close, the company made the maximum use of the digital platform to speed up its interactions with consumers. While overall sales have been sluggish, Nike's online marketing has done well, with digital revenue up $79 \%$ from a year earlier, accounting for about $30 \%$ of total revenue [7]. Therefore, online business and digital platforms could help NIKE to cope with any uncertainties, such as the epidemic.

Besides, to adapt to the current network and digital globalization, several businesses are conducted online. Chief Executive John Donahoe of NIKE said in an email to employees that digital marketing has been a traditional strength of the company, and in the future, the company will restructure its internal resources to further focus on this area of strength, with online sales expected to account for 50 percent of sales, up from 30 percent in the previous quarter [7]. As for Nike, most of its online sales in China are concentrated on the Tmall platform. Since foreign brands are not familiar with the Chinese market and there are some legal barriers, Nike's operation in China's e-commerce platform is mostly completed by its agents and distributors. The market environment in China is more complex, and many regions are beyond the reach of e-commerce platforms. Also, due to the dependence of sales on third-party platforms, Nike can only get desensitized sales data with relatively coarse granularity, which is still a problem whether it is enough to conduct a more in-depth analysis on customers purchasing behaviors [7].To make the largest profit and benefits of NIKE, it should adjust its selling mode to keep pace with the network development by creating localized online selling methods. 


\subsection{Threats}

Firstly, the financial performance of NIKE could be easily influenced by the uncertainties of the economy and the fluctuations of taxes worldwide. A large portion of NIKE's products are manufactured and sold outside of the U.S, and NIKE conducts trade processes in several currencies. So, global economic conditions, including fluctuations in taxes, policies, and foreign currency exchange rates will play important roles in NIKE's overseas business. Foreign currency exchange rate fluctuations can bring defects to the business of manufacturers that produce NIKE products. Since these factories have to purchase raw materials, the change in foreign currency exchange rate would make it more expensive and more difficult to buy those necessities. Uncertainties of the global economy could not be generated by companies, it is a big varying context of the trading system which could partially determine the future of companies, especially those that are expended worldwide.

Secondly, the threats come from the intense competitors of NIKE. As being a top company in the consumer products industry, NIKE has a great number of competitors, especially Adidas. Direct channels have strong control over terminals and can quickly respond to the market. Therefore, Nike keeps expanding direct channels, with the number of direct stores increasing from 858 in 2014 to 1,152 in 2019. On contrary, Adidas owns more retail stores. But to boost single-store profitability, Adidas closed some poorly run stores and streamlined the number of stores, from 2,913 in 2014 to more than 2,300 in 2018, before expanding again to more than 2,500 in 2019 [8]. Therefore, in terms of the number of direct channels, Adidas is far ahead of Nike in the number of stores. It is a chance for NIKE to enlarge its direct channels, which may help NIKE to become more competitive and keep its predominance in this industry.

Thirdly, the negative impact of the epidemic on business performance should be considered. According to the research which is carried by Ming Lv [9], it mentions that due to the impact of the epidemic, in the fourth quarter of 2020, about $90 \%$ of Nike's self-operated stores were closed for about 8 weeks, which significantly affected the company's 2020 Q4 performance. What is more, due to the suspension of the company's wholesale partners, the wholesale quantity decreased by nearly $50 \%$, which reduced Q4 revenue and increased inventory. Although stores are gradually resumed operation since mid-May, it is still a challenge for NIKE to quickly adjust itself to normal business patterns and prepare to face the second outbreak of the COVID-19.

\section{CONCLUSION}

Because of the emergence of the coronavirus in 2020, NIKE had a relatively weak performance in contrast with its performance in 2019. Nevertheless, the most important indexes such as gross margin remain in a stable ratio, which means that NIKE has a strong ability to operate and earn profits. Also, the online business on the digital platform helps NIKE to go through the epidemic period, which reduces the loss in the fourth quarter in 2020. The managers have recognized the weakness NIKE has and they are committed to improving it. As soon as the coronavirus has been eliminated, NIKE may become more profitable and recover its regular operations.

In the case of special situations such as the presence of COVID-19, the sporting goods industry's companies should develop digital platforms and online business, which could make it more convenient for consumers to purchase goods online. An online business would be a chance for NIKE to create more profits. NIKE Digital has already grown 79 percent in Greater China, where the company's annual Digital revenue exceeded $\$ 1$ billion for the first time. Moreover, due to the analysis, China has been considered as a large potential market. To maximize the profits and explore more latent consumers, sporting goods companies (such as NIKE, Adidas) should innovate and provide more special products for Chinese consumers.

This article briefly analyzes the financial performance and attributes of NIKE in 2020 and provides suggestions for future development, however, it would be better to analyze Adidas and other sporting goods brands as supplements. For example, investigate Adidas' financial performance and the sporting goods market in Greater China in fiscal 2020. These valuable researches could reflect the current situation of the whole industry more effectively.

\section{ACKNOWLEDGMENT}

I am thankful to my research project professor $\mathrm{Mr}$. Feng Zhu (Havard Business School), for his valuable guidance and encouragement. His teaching inspires me to finish this research analysis paper.

\section{REFERENCES}

[1] J.J. Donahoe II; Annual report pursuant to section 13 or 15(D) of the securities exchange act of 1934 for the fiscal year ended May 31, 2020.

[2] E. Low. Why Nike Has More Patents Than Lockhead, Ford, And Pfizer; Investors' Business Daily; 05/13/2016.

[3] Nike and Brand Loyalty. UKEssays; 07/07/2017.

[4] T.J. Ryan. Nike Dominates NBA Player Endorsements; SGB Media; 01/01/2014.

[5] DICK'S Sporting Goods Quick Ratio 2006-2020 DKS; Macrotrends.net. 
[6] Y. Li, L. Zhao, M. Wang, K. Zheng, Z. Ren. Analysis on the development prospect of Nike in China market.

[7] L. Ji. Nike's digital empire Morketing depth; Tencent News; 07/03/2020.

[8] Foresight Industry Research Institute. In general, Nike is stronger than Adidas in the competition pattern analysis of China's sneaker and apparel industry in 2020; Foresight Industry Research Institute; 08/20/2020.

[9] M. Lv. Industry weekly report of KaiYuan securities: Nike FY2020Q4 Greater China revenue turned positive, continue to be optimistic about the sports apparel industry chain. 